\title{
Multimedia Interaktif "Belajar Kosa-Kata Bahasa Arab" Sebagai Media Edukasi Belajar Bahasa Arab Untuk Anak Sd Kelas IV
}

\author{
Kadariah, Ahmad Hamim Thohari, Riwinoto \\ * Informatics Engineering, Batam State Polytechnic \\ *** Multimedia and Network Engineering, Batam State Polytechnic
}

Article Info

Keyword:

Learning Media, unity, Arabic, interactive multimedia

\begin{abstract}
Appropriate and appropriate learning methods in educating children are very important things. With interactive multimedia technology that is widespread, we can use it as a learning media. Interactive multimedia development makes it possible to create an interactive educational media called "Learning Arabic Vocabulary". The making of interactive multimedia "Learning Arabic KosaKata" is designed based on a case study from the Elementary School (AlAzhar Elementary School) that applies Arabic language learning. Using the right and varied media in the learning process can increase learning motivation and can reduce student passivity (Hardianto,2005). Vocabulary learning is a very important material in language learning. A person will not be able to speak a language before he enriches himself with vocabulary from that language. Likewise with children in this case. After the survey and interview conducted at Al Azhar Elementary School located at Tiban 1, Patam Lestari, Kec. Sekupang, Batam City Prov. Riau Islands, on October 31,2018 , the parties from the school in question were very hopeful that this interactive multimedia "Learning Arabic Kosa-Kata" could immediately be ready for distribution.
\end{abstract}

Copyright (C) 2020 Multimedia and Network Engineering. All rights reserved.

\section{Corresponding Author:}

First Author,

Multimedia and Network Engineering,

Batam State Polytechnic,

Jl Ahmad Yani Batam Kota, Kota Batam Kepulauan Riau Indonesia .

Email: kadariahria645@gmail.com

\section{Pendahuluan}

Metode dalam pembelajaran semakin berkembang, salah satunya adalah multimedia interaktif. Menggunakan media yang tepat dan bervariasi dalam proses pembelajaran dapat meningkatkan motivasi belajar dan dapat mengurangi sikap pasif siswa (Hardianto, 2005). Dengan begitu terdapat peluang untuk kita manfaatkan teknologi ini dalam mendidik anak bangsa dengan pengajaran yang lebih kreatif dan menyenangkan. Dengan membuatkan mereka sebuah media edukasi, membantu mereka dalam proses belajar memahami hal baru tanpa mengurangi waktu bermain mereka. Karena teknologi pada multimedia interaktif mampu menyajikan banyak keunggulan mulai dari tampilan visual yang menyenangkan, dan terdapat juga permainan yang disajikan sehingga membuat anak-anak tidak jenuh ketika belajar hanya 
dengan mendengarkan penjelasan dari guru tanpa alat bantu seperti media edukasi yang bisa membuat proses belajar mengajar menjadi lebih efektif. memanfaatkan perkembangan teknologi dalam kemudahan aktivitas sehari-hari adalah hal yang lazim dilakukan. Termasuk dalam segi pendidikan dan pembelajaran anak di sekolah. Pengembangan multimedia interaktif sebagai media edukasi juga sangat diperlukan untuk membantu tumbuh kembang mereka dalam menimba ilmu pengetahuan dalam hal ini khususnya belajar kosa-kata bahasa arab.Pembelajaran dengan memanfaatkan teknologi multimedia interaktif dalam hal edukasi sudah merambah keseluruh aspek kehidupan, tanpa terkecuali dibidang pendidikan juga. Seorang guru, dituntut untuk mampu menghadirkan metode-metode belajar yang menyenangkan untuk para murid. Dengan memanfaatkan teknologi yang ada, pembelajaran dapat disajikan dalam sebuah aplikasi siap pakai, yaitu multimedia interaktif "Belajar Kosa-Kata Bahasa Arab". Dimana dapat dimanfaatkan sebagai sarana belajar ana-anak dalam hal ini, belajar kosa-kata bahasa Arab.

\section{Metode Penelitian}

Dalam pembuatan aplikasi ini menggunakan metodologi pengembangan multimedia versi Luther Sutopo (2003). Dalam metodologi ini terdiri dari enam tahapan kerja untuk membangun aplikasi,yaitu concept (pengonsepan), desaign (pendesainan), material collecting (pengmpulan materi), assembly (pembuatan), testing (pengujian), dan distribution (pendestribusian). Adapun gambaran siklus tahapan kerja pada metodologi ini Dapat dilihat pada gambar dibawah.

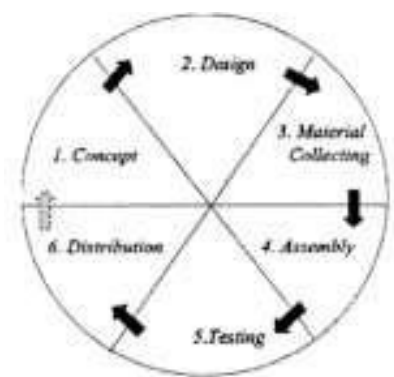

Gambar 1. Tahapan pengembangan multimedia

\section{Concept}

Aplikasi yang akan dibuat adalah multimedia interaktif sebagai media pembelajaran untuk mengenal kosa-kata bahasa arab sederhana berbasis deskstop menggunakan sofware Unity. memuat 3 tombol button yaitu, tombol belajar, tombol permainan, dan juga tombol petunjuk.

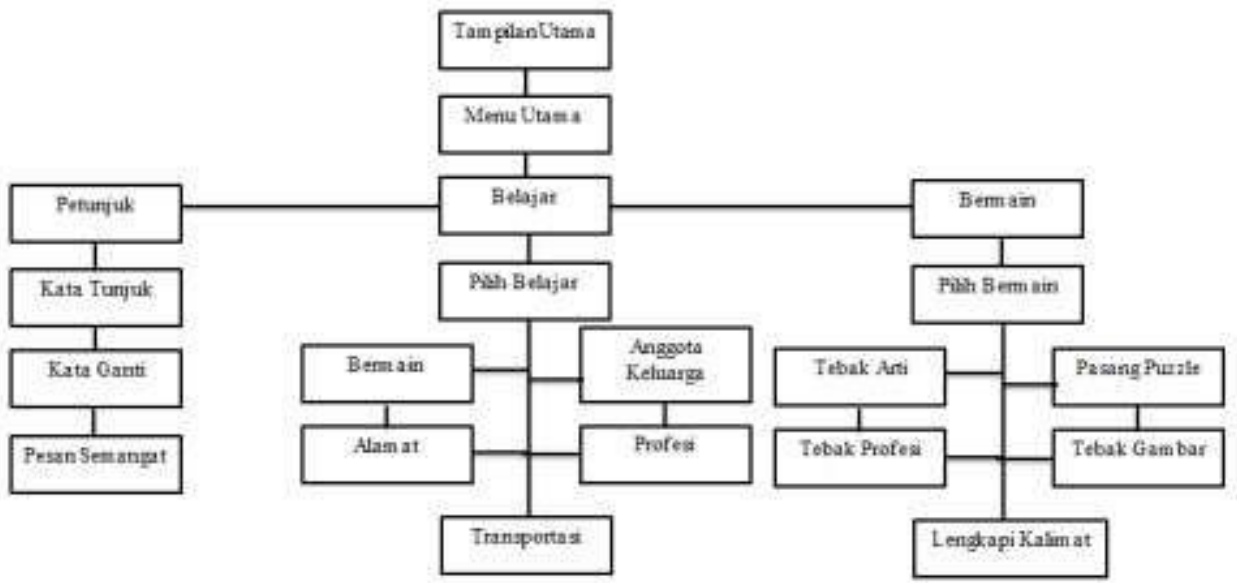

Gambar 2. Analisis interaksi

\section{Desain}

Pada tahap ini mulai merancang dan menentukan desain-desain layout yang diinginkan untuk tampilan awal hingga akhir. Layout-layout yang sudah di sketsa dalam bentuk lukisan pada kertas Hvs putih. Desain pada tahap ini berupa storyboard yang menjadi acuan pada tahan selanjutnya yaitu assembly adapun desain yang dirancang adalah sebagai berikut: 


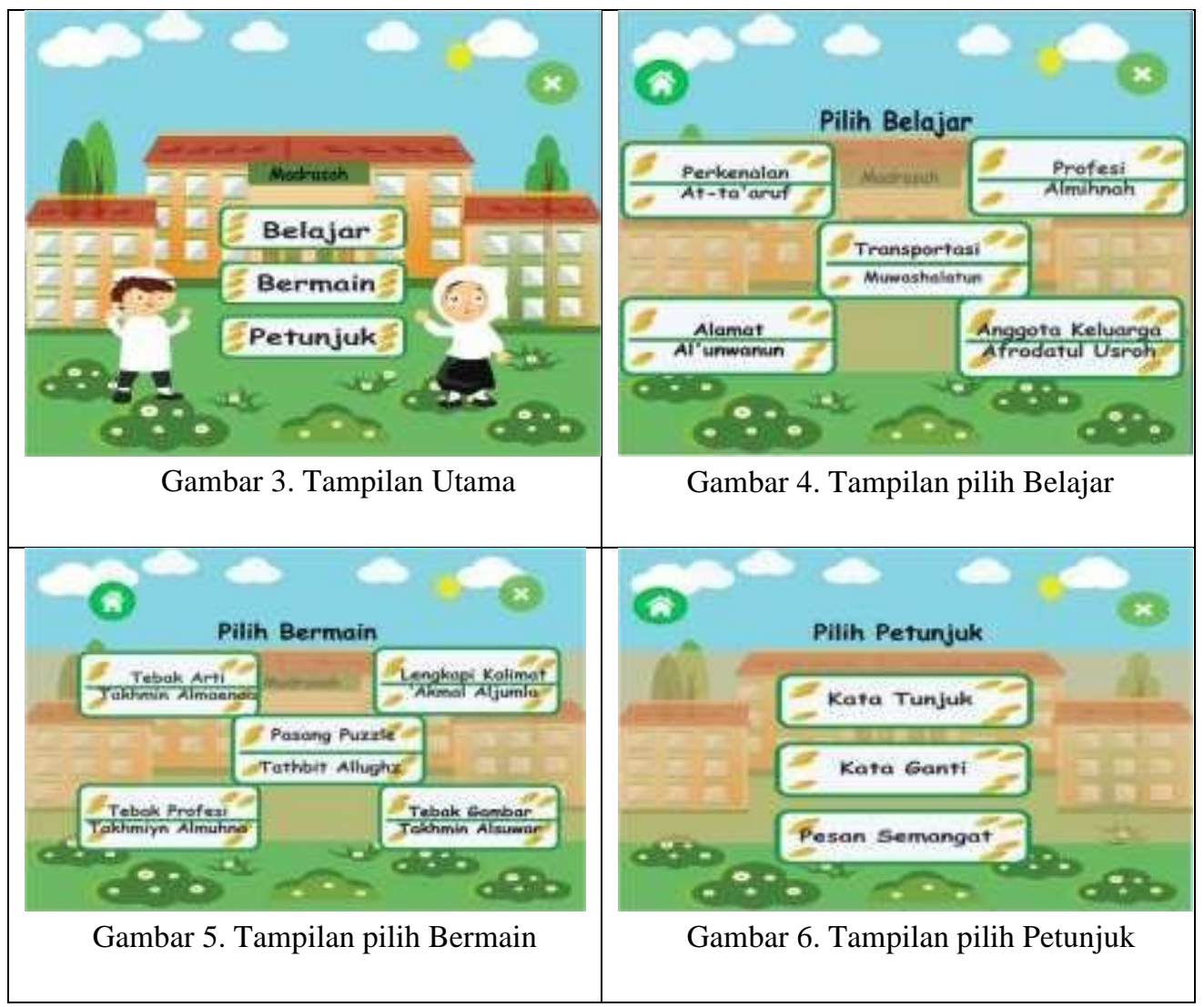

\section{Materia Collecting}

kita mengelompokkan komponen apa saja yang diperlukan disetiap layout scene "Belajar Kosa-Kata Bahasa Arab" yang di rancangkan. Materi meliputi gambar-gambar yang ditampilkan, teks yang ditampilkan, button yang ditampilkan dan atribut lainnya yang digunakan sesuai dengan kebutuhan dalam perancangan.

Tabel 1. Material Collecting

\begin{tabular}{|c|c|c|c|}
\hline No & Nama & Tipe & Keterangan \\
\hline 1 & $\begin{array}{l}\text { Tampilan Awal } \\
\text { 1.Gambar } \\
\text { 2.Teks } \\
\text { 3.Tombol } \\
\text { (Belajar,Bermain,dan } \\
\text { Petunjuk) } \\
\text { 4.Audio }\end{array}$ & $\begin{array}{l}\text { Png } \\
\text { Teks } \\
\text { Button } \\
\text { Mp3 }\end{array}$ & $\begin{array}{l}\text { Dibuat: } \\
\text { Ditracing Menggunakan } \\
\text { Adobe illustrator cs } 6\end{array}$ \\
\hline 2 & $\begin{array}{l}\text { Pilih Belajar: } \\
\text { 1.Gambar } \\
\text { 2.Teks } \\
\text { 3.Tombol } \\
\text { 4.Audio }\end{array}$ & $\begin{array}{l}\text { Png, Teks } \\
\text { Teks } \\
\text { Button } \\
\text { Mp3 }\end{array}$ & $\begin{array}{l}\text { Dibuat: } \\
\text { Ditracing Menggunkan } \\
\text { Adobe illustrator cs6 } \\
\text { Dubbing }\end{array}$ \\
\hline
\end{tabular}




\begin{tabular}{|c|l|l|l|}
\hline 3 & Pilih Bermain: & Dibuat: \\
& $\begin{array}{l}\text { 1.Gambar } \\
\text { 2.Teks } \\
\text { 3.Tombol }\end{array}$ & $\begin{array}{l}\text { Teks } \\
\text { Button } \\
\text { Ditracing Menggunkan } \\
\text { Adobe illustrator cs6 } \\
\text { Dubbing }\end{array}$ \\
\hline 4 & $\begin{array}{l}\text { Pilih Petunjuk: } \\
\text { 1.Gambar } \\
\text { 2.Teks } \\
\text { 3.Tombol }\end{array}$ & $\begin{array}{l}\text { Png } \\
\text { Teks } \\
\text { Button }\end{array}$ & $\begin{array}{l}\text { Dibuat: } \\
\text { Ditracing Menggunkan } \\
\text { Adobe illustrator cs6 }\end{array}$ \\
\hline
\end{tabular}

\section{Assembly}

proses lanjutan yang berfokus pada pembuatan tampilan visual dari aplikasi multimedia interaktif "Belajar Kosa-kata Bahasa Arab". Pada fase ini meliputi pembuatan, objek pendukung serta tampilan visual.

\section{a. Dubbing}

Dubbing merupakan fase assembly yang pertama yakni berfungsi sebagai suara dari pengucapan kosa-kata bahasa arab yang ada pada setiap bab belajar. Dalam hal ini dubbing berfungsi sebagai audio cara pengucapan kosa-kata dalam bahasa arab yang tersedia dalam bab Belajar pada aplikasi "Belajar Kosa Kata Bahasa Arab".

b. Implementasi Storyboard pembuatan background

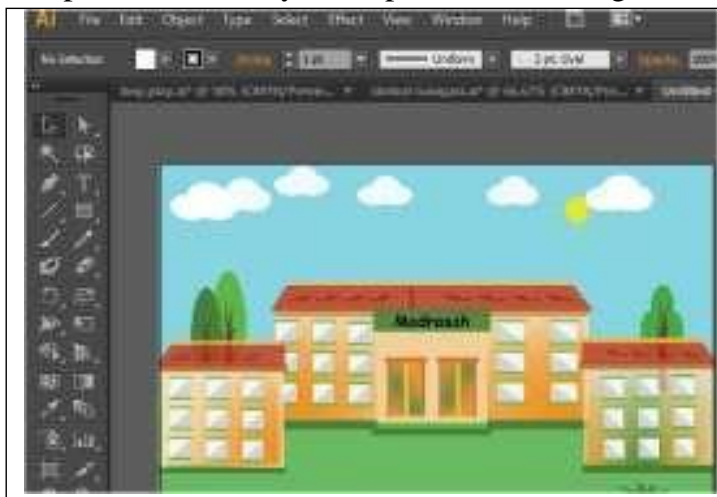

Ket: Gambar 7. disamping adalah rancangan background pada menu utama

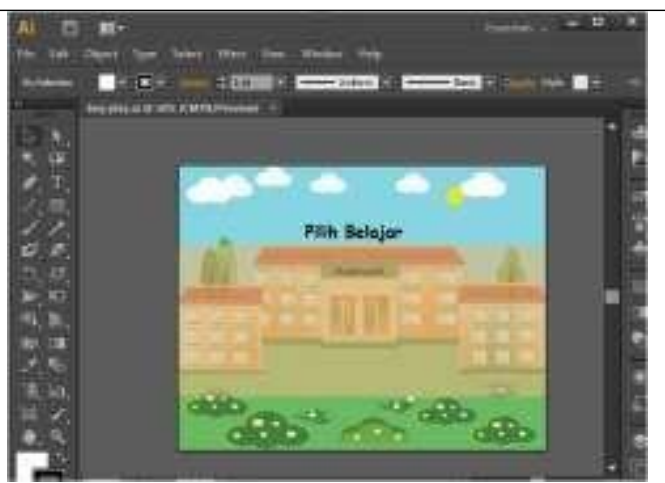

Ket: Gambar 8. Berikut adalah gambar pada saat pembuatan backgroundsecara keseluruhan untuk tampilan scene Belajar, Bermain, dan petunjuk

c. Pembuatan tombol-tombol navigasi

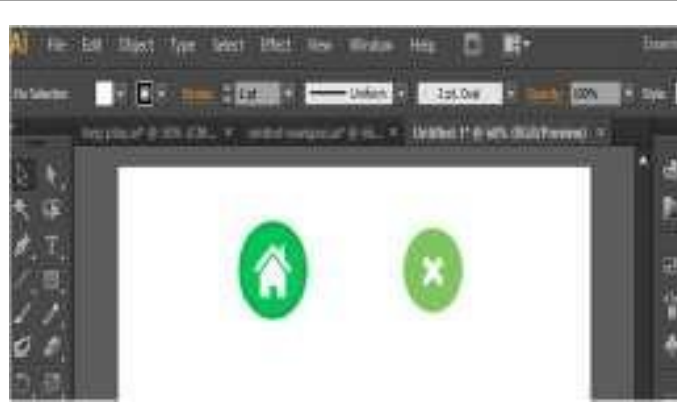

Ket: Gambar 9. disamping adalah rancangan background pada menu utama

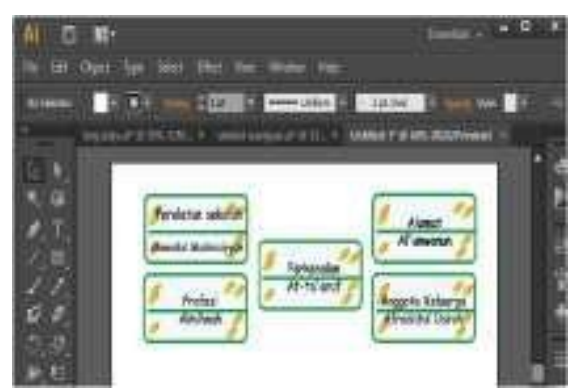

Ket: Gambar 10. Pembuatan tombol-tombol pada menu belajar 


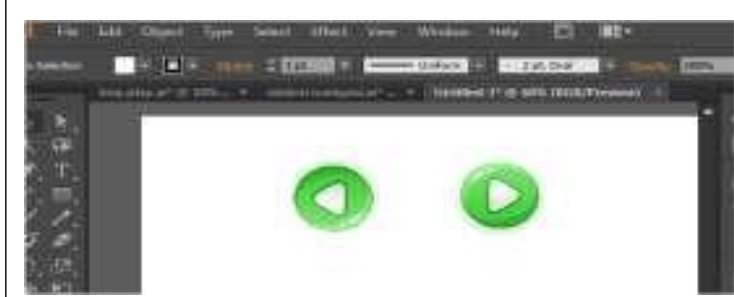

Ket: Gambar 11. Pembuatan tombol-tombol pada next dan prev yang terdapat pada bab belajar

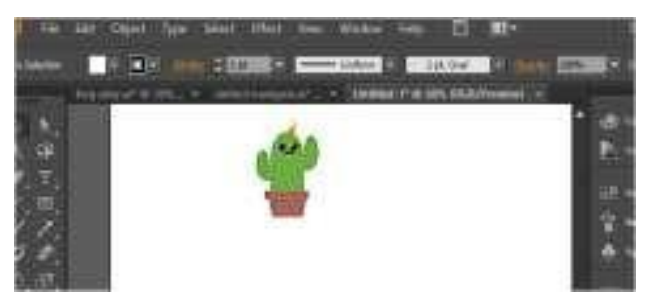

Ket:Gambar 12. Tombol yang berfungsi untuk menampilkan pilihan bermain pada bab bermain

\section{d. $\quad$ Coding}

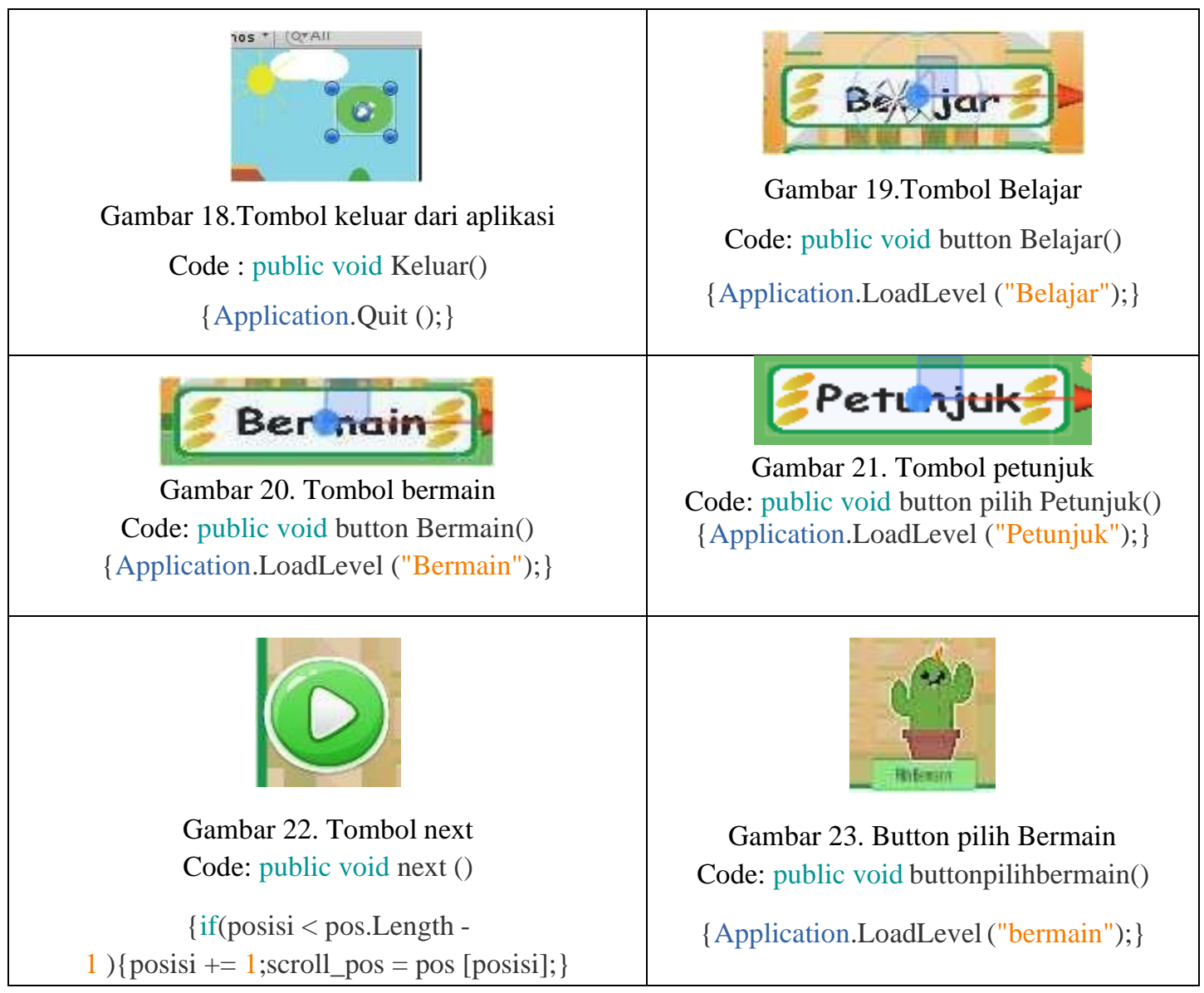

\section{Testing}

Setelah melalui tahap Assembly dan pembuatan aplikasi, masuk ke tahap testing yaitu dimana aplikasi sudah mampu unutk dijalankan secara keseluruhan maka dilakukan pengujian sistem.Dalam hal ini pengujian yang digunakakan untuk memeriksa sistem adalah pengujian alfa untuk sisi fungsi dan Beta untuk sisi pengguna.

Tabel 2. Pengujian fungsi tombol

\begin{tabular}{|l|l|l|l|l|}
\hline No. & Tombol pada aplikasi & Keterangan & Berfungsi & $\begin{array}{l}\text { Tidak } \\
\text { Berfungsi }\end{array}$ \\
\hline 1. & & $\begin{array}{l}\text { Tombol untuk } \\
\text { keluar aplikasi }\end{array}$ & Berfungsi & \\
\hline
\end{tabular}




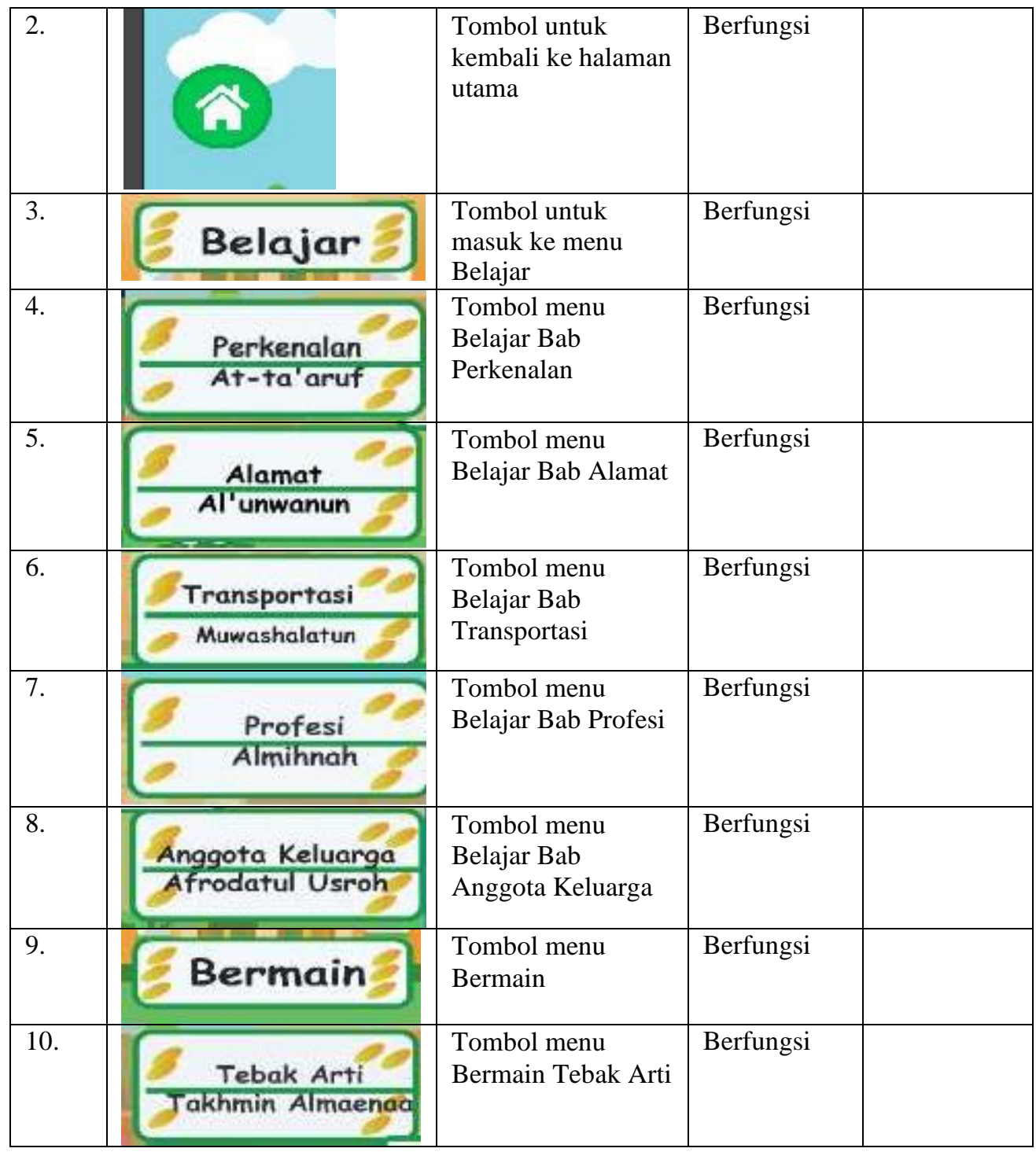

\section{Distribution}

Setelah berhasil pada pengujian alpha, maka file produk multimedia interaktif "Belajar Kosa-kata Bahasa Arab" pada software unity, dapat di export kedalam format file exe sehingga file dapat dijalankan (run) baik di PC maupun laptop,dan a aplikasi multimedia interaktif "Belajar Kosakata Bahasa Arab" siap untuk digunakan.

\section{Hasil dan Pembahasan}

Dengan menggunakan kuesioner berupa sepuluh (10) butir pertanyaan seputar fungsi dari aplikasi multimedia interaktif "Belajar Kosa-kata BahasaArab" dan penghitungan dari kuesioner enggunakan metode skala likert dapat dilihat hasil dari kuesioner sebagai berikut: 


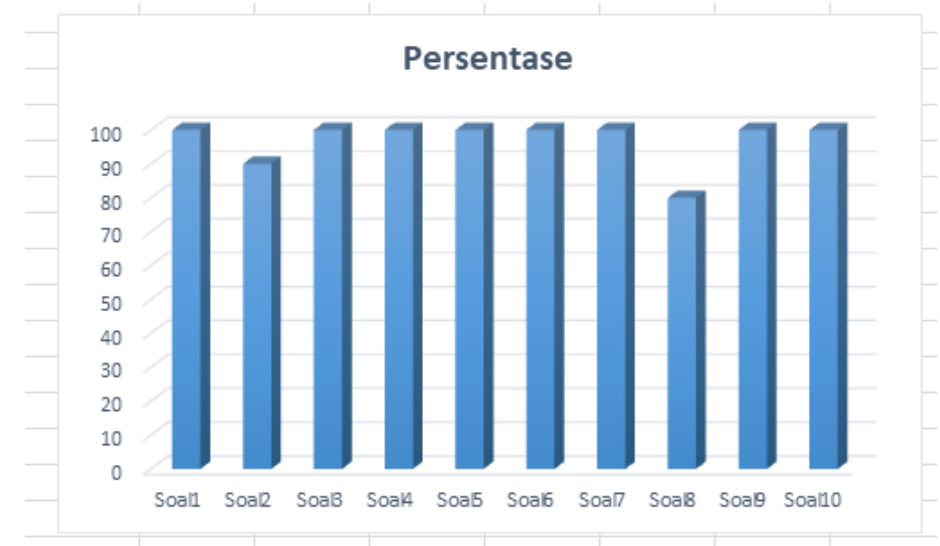

Gambar 24. Hasil jawaban kuesiner

keseluruhan nilai dari masing-masing soal yaitu:

Tabel 3. persentase dari kuesioner
\begin{tabular}{|c|c|}
\hline Pertanyaan $1=100 \%$ & Pertanyaan 6 $=100 \%$ \\
\hline Pertanyaan $2=90 \%$ & Pertanyaan 7 $=100 \%$ \\
\hline Pertanyaan 3 $=100 \%$ & Pertanyaan $8=80 \%$ \\
\hline Pertanyaan 4 =100\% & Pertanyaan 9 $=100 \%$ \\
\hline Pertanyaan 5 = 100\% & Pertanyaan 10=100\% \\
\hline
\end{tabular}

\section{Kesimpulan}

1. Penelitian ini menggunakan metode Luther Sutopo untuk memulai atau memetakan langkah kerja dalam pengembangan aplikasi multimedia interaktif "Belajar Kosakata Bahasa Arab"

2. Dalam penelitian ini telah berhasil menyajikan pembelajaran kosakata Bahasa Arab kedalam multimedia interaktif dengan hasil output aplikasi yang berekstensi .exe dari software unity.

3. Dari hasil kuesoiner yang didapatkan rentang nilai sebesar $97 \%$ yang membuktikan bahwa apliksai multimedia interaktif yang dibangun dapat dijadikan alat bantu dalam mengajar di kelas.

\section{Ucapan Terimakasih}

Terimakasih kepada pihak Sekolah Dasar Al-Azhar dan Sekolah Dasar Tunas Cendikia,. yang sudah banyak membantu dalam pelaksanaan penelitian pengembangan multimedia interaktif "Belajar Kosa-kata Bahasa Arab” sebagai media pembelajaran untuk siswa kelas IV ini sampai selesai.

\section{REFERENCES}

Ahmad, Abdul Karim H. 2007. Media Pembelajaran. Makassar: Badan Penerbit

Universitas Negeri Makassar.

Badriyah Tessy. 2017. UML Class Diagram. Modul Pembelajaran Politeknik

Elektro Negeri Surabaya.

Deni Hardianto, 2005, Media Pendidikan Sebagai sarana Pembelajaran yang

Efektif. MajalahIlmiah Pembelajaran, Vol.(1), 95-104

Fakhrizal. 2016. Pengertian Multimedia Interaktif. Jurnal Ilmiah.

Mahafi Galang Aditya, Hermawan Galih. 2013. Game Edukasi Penyakit Malaria

Dan Carapencegahannya. Jurnal Ilmiah Komputer dan Informatika.

Metode Finite State, Jurnal Tugas Akhir Politeknik Negeri Batam.

Purba Valdano Ricky, 2017, Aplikasi Ayo Belajar Pengenalan Huruf dan

Membaca Berbasis Android, Jurnal Tugas Akhir Politeknik Negeri Batam.

Rosyanto. Pengolahan AudioKompetensi Keahlian Multimedia SMK Kelas XI.

Rusman. 2012. Belajar dan Pembelajaran Berbasis Komputer. Bandung: Alfabeta. 